filmen? Um das zu bewerkstelligen, arbeitet Ekaterina Eremenko gelegentlich als embedded scientist. Sie zeigt ihre eigenen Kolleginnen und Kollegen, wie sie einen Vortrag halten oder ihre Kinder mit ins Büro bringen.

In einer Szene aus The Discrete Charm of Geometry steht ein Mann vor einer Tafel und sagt halb zu sich, halb zu den Umstehenden: „It is, it is, it is.“ Ja, was ist es denn? möchte man fragen. Dabei klopft er gegen die Tafel, als müsse sie durchbohrt werden. Der begriffsarme Text und das Klopfen wirken wie ein unfreiwilliges Sinnbild, dass das Nachdenken ins Stocken gerät. Man kann regelrecht zusehen, wie der Verstand nach dem richtigen Begriff sucht, um eine Sache $\mathrm{zu}$ fassen, von der noch niemand weiß, what it is.

Vielleicht sind solche Gespräche - wenn man „it is, it is, it is" ein Gespräch nennen mag - der tiefere Grund, weshalb wir bei unseren Kolleginnen und Kollegen die Äußerlichkeiten glatt übersehen: Wir brauchen die wenigen anderen, denen dieselben Fragen und Ideen durch den Kopf rasen wie uns selbst, nur mit einem leicht anderen Drall. Im Gespräch stoßen die Ideen zusammen und man kommt manchmal ein
Stück weiter. Das Zusammenkommen mit den anderen ist unser Teilchenbeschleuniger.

Wer selbst wenig Kontakt mit der Mathematik als Forschung hat, findet in den Filmen von Ekaterina Eremenko ein authentisches Bild dessen, was es heißt, Mathematiker zu sein. Und für Mathematiker sind ihre Filme eine Gelegenheit, unsere eigene Arbeit - frei von den Klischees über Wunderlichkeit und Genie - von außen zu beobachten. Vielleicht zeigt sie sogar jene Augenblicke, in denen Mathematik wirklich passiert. Sind es nicht am Ende diese Augenblicke, für die wir Mathematiker geworden sind?

Ekaterina Eremenko hat für ihre Filme 2017 den Medienpreis der DMV erhalten. Dieses Jahr gibt es wieder einen Medien- und einen Journalistenpreis. Die Preisverleihung findet am 1. November in den Räumen der PTB in Berlin statt. Kommen Sie doch auch. Man darf auf großartige Preisträger und einen anregenden Abend zur Wissenschaftskommunikation hoffen.

Sebastian Stiller

\title{
Mathematik-Professorinnen und -professoren an Universitäten in Deutschland
}

\author{
Das Problem der Zahlen
}

Wir haben eine Reihe von Zuschriften zur Karte der Professorinnen und Professoren erhalten. Vielen Dank dafür! Sie helfen uns, die Daten in der Karte, die unter www.mathematik.de/professorinnen-und-professoren online steht, $\mathrm{zu}$ korrigieren und $\mathrm{zu}$ aktualisieren.

In der Karte sollen alle bezahlten Professorinnen und Professoren der Mathematik repräsentiert werden. Wer das genau ist, überlassen wir den Standorten. Insbesondere lässt sich von außen nicht gut entscheiden, wer sich zur Mathematik zählt und wer nicht.
Wir möchten Sie bitten, uns auch weiterhin diese Informationen zukommen zu lassen. Bitte benutzen Sie hierfür ausschließlich die E-Mail-Adressedmv@wias-berlin.de. Das erleichtert es uns, den Überblick zu behalten.

In der bisherigen Karte sind nur Universitäten verzeichnet. Wir sehen aber überhaupt keinen Grund, andere Hochschulen nicht zu erfassen: Wir freuen uns, wenn uns auch diese ihre Daten zusenden. Es kann sein, dass wir irgendwann einmal die Karte in zwei Teile werden aufteilen müssen, damit sie leserlich bleibt. 


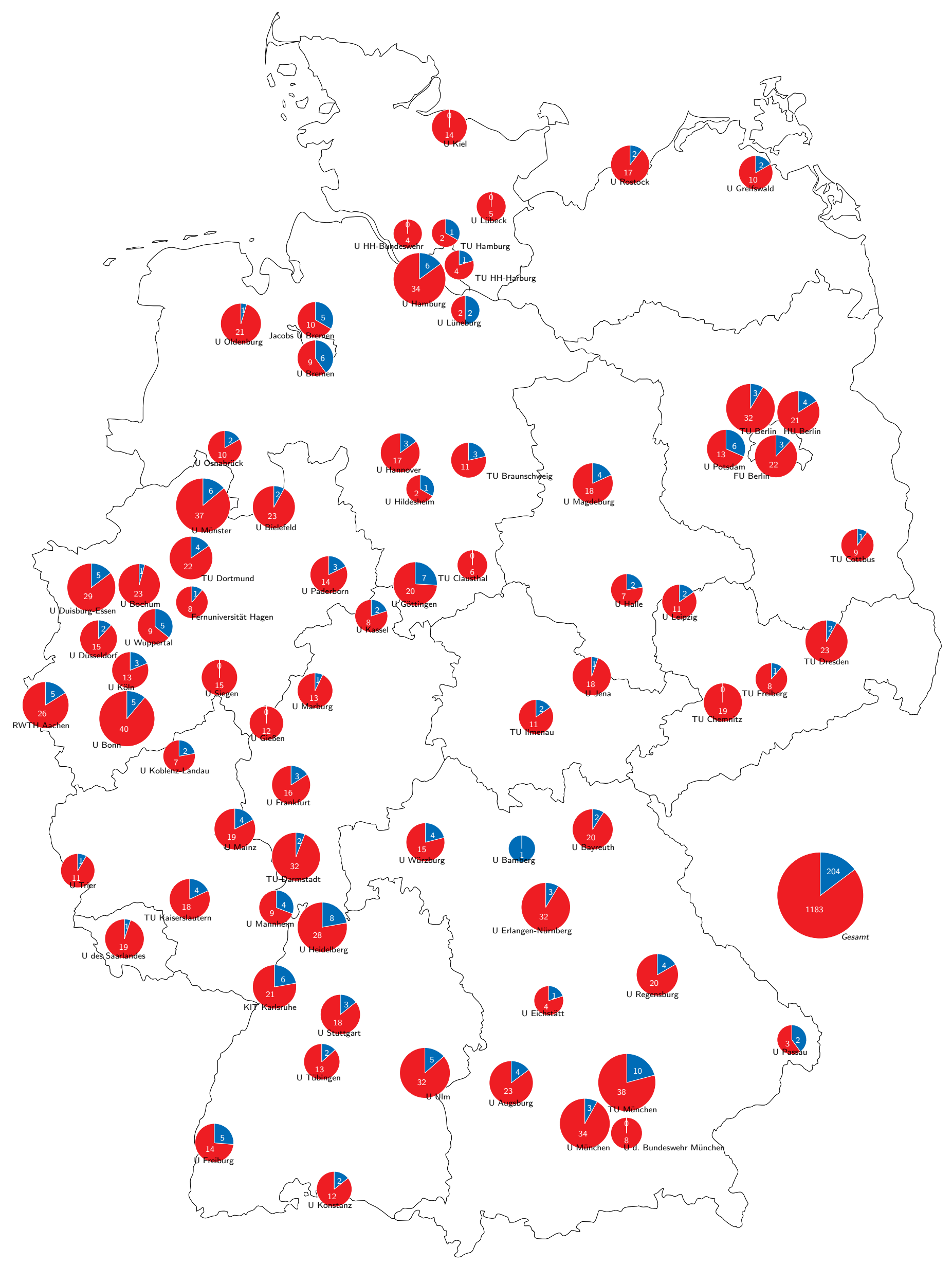

Darstellung: Christoph Eyrich. Umrisskarte: www.d-maps.com/m/europa/germany/allemagne/allemagne5o.pdf 